\title{
NMR and ESR investigation of the humification processes in defined vegetable starting materials
}

\author{
G. Almendros ${ }^{1}$, R. Fründ ${ }^{2}$, F.J. Gonzales-Vila ${ }^{3}$, H.-D. Lüdemann ${ }^{2}$, F. Martin ${ }^{3}$ \\ ${ }^{1}$ Instituto de Edafologia y Biologia Vegetal, C.S.I.C., Madrid, Spain \\ 2 Institut für Biophysik und Physikalische Biochemie, NWF III, Universität Regensburg, Regensburg, F.R.G. \\ ${ }^{3}$ Centro de Recursos Naturales y Agrobiologia, C.S.I.C., Sevilla, Spain
}

Eingegangen: 3. Oktober 1986

Angenommen: 21. Januar 1987

\section{Summary - Zusammenfassung}

The C-13 spectra at 75.4 Mat of various leaf and needle composts are atudied as a function of the composting time, and the chemical changes observed aro discussed.

In addition, the C-13 spectra of humic acids produced from typical composted Mediterranean horticultural and agricultural vaste like grapevine prunings, grape busks and wheat straw are examined.

The spectra from all materials show incrensingly poorer resolu. tion with ineressing composting time.

No new C-13 signals to indicate the formation of ney chemical entities are scen to occur during the process of composting.

It is showa by quantitative ESR that the deterioration of the quality of the MMR spectra is not dre to formation of additional free radicals during the composting process.

\section{Introduction}

C-13 NMR is one of the most useful spectroscopic techniques currently available for the characterization of humic substances. Its application to aqueous solutions of these substances is, however, limited by the low signal to noise ratio. By using a modern high field spectrometer operating at $B_{0}$-fields $\geqslant 7$ Tesla, sensitivity can be sufficiently increased to obtain decent spectra after an accumulation time of approx. 6 hours.

It thus becomes feasible to study series of humic acids isolated from lignocellulosic materials and composted leaves, and to determine the effect of the various starting materials on the chemical composition of the final products. The results presented later relate to an investigation of the humification process in various defined starting materials of plant origin under well controlled conditions by means of C-13 NMR spectroscopy, weight loss measurements and elementary analysis.

The materials used in this study included leaves and needles from eight different typical Mediterranean trees and shrubs, wheat straw, grape husks and grapevine prunings. The latter three materials are produced in large quantities in Mediterranean agriculture and winegrowing, and lend them-

\section{NMR - und ESR-Untersuchungen des Humlinierumgsprozesces von definierten pinmlichen Ausgangomateriblien}

Es werden die C-13 Spektren bei 75, 4 MHz verschiedener Laubund Nadelkomposte als Funktion der Kompostierungszeit mitgeteilt und die beobachteten chemischen Veränderungen diskutiert. Auberdem werden die $C_{13}$ Spektren der Huminsäuren, die aus typischen mediterranen landwirtschaftliehen Abfallen, wie Weintebenbeschnitt, Trester und Weizenstroh erzeugt werden, untersucht. Die Spektren aller Substanzen zeigen mit zunchmender Zeitdauer schlechtere Auflosung. Wahrend der Kompostierung treten keine weiteren C-13 Signale, die die Blldung neuer chemischer Strukturen anzeigen wirden, auf.

Es wird durch quantitative ESR Untersuchungen nachgewiesen, daß die Verschlechterung der NMR-Spektren nicht durch eine Zunahme der freien Radikalkonzentration wahrend des Kompo. stierens verumacht wird.

selves to application to soils for the purpose of improving the fertility of intensively cropped land.

The effect of added nitrogen on the humification process was also studied.

The humic substances consist of a wide variety of chemical structures with a broad distribution of molecular weights. These characteristics inevitably lead in aqueous solutions to great differences in the relaxation rates and line widths. It is, therefore, of fundamental importance to search for experimental conditions which yield a good signal to noise ratio and at the same time facilitate a quantitative evaluation of the spectra. In this paper, the influence of modern pulse programmes on the quality of the spectra is described, and an attempt is made to correlate the quality of the spectra with the concentration of paramagnetic centres of free radicals as determined by ESR. The ESR measurements also yield information about the influence of the humification process on the concentration of the paramagnetic centres.

\section{Materials and methods}

Leaves and needles of the plants Juniperus sabina (JS), Quercus rotundifolia (QR), Ilex aquifolium (IA), Juglans regina (JR), Salix alba (SA), Eucalyptus amygdalina (EA), Pinus radiata (PR) and 
Juniperus communis (JC) were incubated separately without any additives at $30^{\circ} \mathrm{C}$.

Samples were taken from these incubates after 2, 6, 10, 14, 18 and 22 weeks, and freeze-dried. For the NMR measurements, $150 \mathrm{mg}$ portions of the dry residues were dissolved in $3 \mathrm{ml} 0.5 \mathrm{~N}$ deuterated sodium hydroxide solution. The composts from grapevine prunings, grape husks and wheat straw were extracted with $0.1 \mathrm{~N}$ sodium hydroxide solution, the humic acids were precipitated with hydrochloric acid at $\mathrm{pH} 1$, and purified by repeated re-precipitation, centrifugation and dialysis before they were freeze-dried.

Table 1 gives the composition of the various composts.

Table 1: Starting materials and additives for vine shoot, grape husks and straw composts.

Tabelle 1: Ausgangsmaterialien und Zusätze der Weinrebenbeschnitt-, Trester- und Strohkomposte.

\begin{tabular}{|c|c|c|c|}
\hline Abbreviation & Composition & Additions & $\begin{array}{c}\text { Time of } \\
\text { Composting }\end{array}$ \\
\hline $\mathrm{CO}$ & $\begin{array}{l}\text { husks of grapes } \\
\text { and vine shoots }\end{array}$ & - & $-($ control $)$ \\
\hline C1 &,-- & - & 4 months \\
\hline $\mathrm{C} 2$ &,-- & urea $\mathrm{C} / \mathrm{N}$ ratio 40 & 4 months \\
\hline C3 &,-- & urea $\mathrm{C} / \mathrm{N}$ ratio 30 & 4 months \\
\hline $\mathrm{C} 4$ &,-- & chicken manure $C / N$ ratio 30 & 4 months \\
\hline $\mathrm{C5}$ &,-- & pig manure $\mathrm{C} / \mathrm{N}$ ratio 30 & 4 months \\
\hline $\mathrm{C6}$ &,-- & horse manure $\mathrm{C} / \mathrm{N}$ ratio 30 & 4 months \\
\hline C7 &,-- & $\begin{array}{l}\text { with addition of straw } \\
\text { and grain scraps }\end{array}$ & 4 months \\
\hline Z $1-4$ & husks of grapes & - & 1 month \\
\hline Z 1-8 & $-n-$ & - & 2 months \\
\hline Z 2-4 &,-- & ammonium nitrate & 1 month \\
\hline Z 2-8 & $-n-$ &,-- & 2 months \\
\hline $\mathrm{Z} 4-4$ &,-- & chicken manure & 1 month \\
\hline $\mathrm{Z} 4-8$ &,-- & $-{ }^{-}$ & 2 months \\
\hline AHPCU4 & wheat straw compost & $\begin{array}{l}10 \% \text { horse manure and } \\
\text { urea } C / N \text { ratio } 30\end{array}$ & 4 months \\
\hline AHPOG4 &,-- & $\begin{array}{l}10 \% \text { husks of grapes, } \\
\text { vine shoots and chicken } \\
\text { manure }\end{array}$ & 4 months \\
\hline AHPG4 & $-{ }^{-}-$ & only chicken manure & 4 months \\
\hline AHPRG4 &,-- & $\begin{array}{l}\text { pressed sugar/beet and } \\
\text { chicken manure }\end{array}$ & 4 months \\
\hline
\end{tabular}

The NMR measurements were taken from $150 \mathrm{mg}$ dry substance dissolved in $0.5 \mathrm{~N}$ deuterated sodium hydroxide solution.

All spectra were recorded on a Bruker MSL 300 spectrometer at a frequency of $75.4 \mathrm{MHz}$ in a $10 \mathrm{~mm}$ multinuclear high resolution probe head in the deuterium lock mode.

The protons were continuously broadband decoupled. The spectra were referenced to a capillary filled with neat tetramethysilane. This capillary was put into the NMR tube after each experiment and 100 FID's were accumulated. No attempts to correct for magnetic susceptibility effects were made. The chemical shifts given are judged accurate to $\pm 1 \mathrm{ppm}$.

Several pulse programmes were tested in preliminary experiments. The programme RiDE (Ring Down Elimination) gave the best results (Gerothanassis, 1986). It yielded spectra with reasonably flat baselines to allow integration of the various groups of signals. The RiDE pulse sequence consists of:

$$
90_{+x}^{\circ}-\Delta t-\text { FID }^{(+)}-T_{d}-90^{\circ}-\Delta t-\text { FID }^{(\cdot)}-T_{d}-180_{+y}^{\circ}-90^{\circ} \cdot-
$$$$
\Delta \mathrm{t}-\text { FID }^{(+)}-\mathrm{T}_{\mathrm{d}}-180_{+y}^{\circ}-90_{+\mathrm{x}}^{\circ}-\Delta \mathrm{t}-\text { FID }^{(-)}-\mathrm{T}_{\mathrm{d}}
$$

$\mathrm{T}_{\mathrm{d}}$ was set to $0.5 \mathrm{~s}, \Delta \mathrm{t}$ to $20 \mu \mathrm{s}$, and 30000 FID's with an acquisition period of $0.16 \mathrm{~s}$ were accumulated.
The spectral width of the recorded spectra extended from $80 \mathrm{ppm}$ to $250 \mathrm{ppm}$. Only the region between 0 and $190 \mathrm{ppm}$ is given in the spectra, this range comprises all signals observed.

The quantitative ESR spectra were obtained on a Bruker ER 220 D LR spectrometer in a double cavity at $9.77 \mathrm{GHz}$ (X-Band) at $300 \mathrm{~K}$. They were calibrated to a standard pitch sample. Under these experimental conditions, only organic free radicals are observable.

The C,H,N determinations were performed by standard microanalytical methods.

\section{Results and discussion}

\section{Composts from leaves or needles}

In order to obtain spectra of good quality suitable for a quantitative evaluation and with a high signal to noise ratio, it is of utmost importance that the spectrometer is carefully 
adjusted (Preston et al., 1985). It is necessary to suppress the nuclear Overhauser enhancement by gated decoupling and to work with a sufficiently long pulse delay in order to avoid saturation effects that otherwise influence the relative intensities. Since a significant fraction of the carbon atoms in humic substances exhibit very short spin-spin relaxation times, it is necessary to work with the lowest acquisition delay possible, and to tolerate interference from acoustic ringing of the coils after the RF pulse and filter ringing. The contributions from these effects lead to an uncorrectable base line curvature, although in principle they can be eliminated by increasing the acquisition delay. However, with spectra extending over a wide range of chemical shifts, such an increase aggravates phasing problems. Therefore, the only solution to this complexity of problems is to use elaborate pulse programmes of the type mentioned beforehand or to use specifically designed cross coil probes.

Figure 1 presents the C-13 spectra of Eucalyptus amygdalina leaves sampled after different times of composting. The spectrum of the untreated starting material shows the best resolution and the highest signal to noise ratio. Most striking is the well resolved region between $60-100 \mathrm{ppm}$ which is ascribed to carbohydrates, and also the aliphatic region from

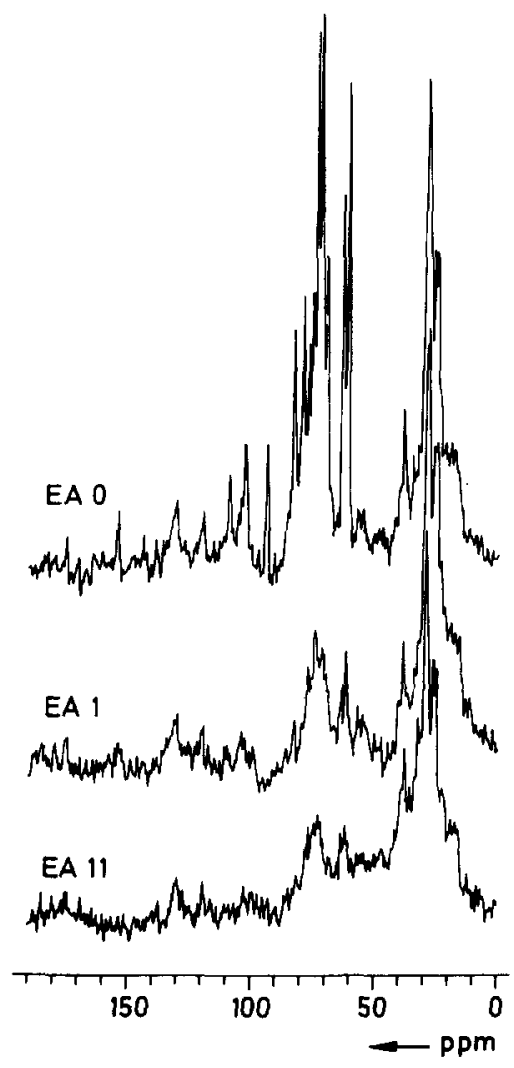

Figure 1: Change of the C-13 spectra of composted Eucalyptus amygdalina leaves with time. EA 0 dried starting material, EA 1 after 2 weeks, EA 11 after 22 weeks incubation time.

Abbildung 1: Veränderung der C-13 Spektren der kompostierten Eucalyptus amygdalina Blätter in Abhängigkeit von der Zeit. EA 0 getrocknetes Ausgangsmaterial, EA 1 nach 2 Wochen, EA 11 nach 22 Wochen Inkubationszeit.
10 to $40 \mathrm{ppm}$ (Gonzalez-Vila et al., 1985). During the process of composting, the relative amount of carbohydrates is significantly decreased, while the aliphatic region becomes enhanced. The most dramatic changes are seen after the first two weeks of composting. The trend appears to continue at a lower rate with increasing time of incubation.

This observation correlates well with the accumulated weight loss curve given in Figure 2, which shows that losses were highest in the first two weeks. The results of the elementary analysis in Table 2 do not show these marked changes. The $\mathrm{C} / \mathrm{N}$ and $\mathrm{C} / \mathrm{H}$ ratios appear to change at a more continuous rate. These latter data are indicative of a slight decrease only in the overall carbon content so that it can be taken for certain that the decrease of the $S / N$ ratio is not ascribable to the reduction of the carbon content.

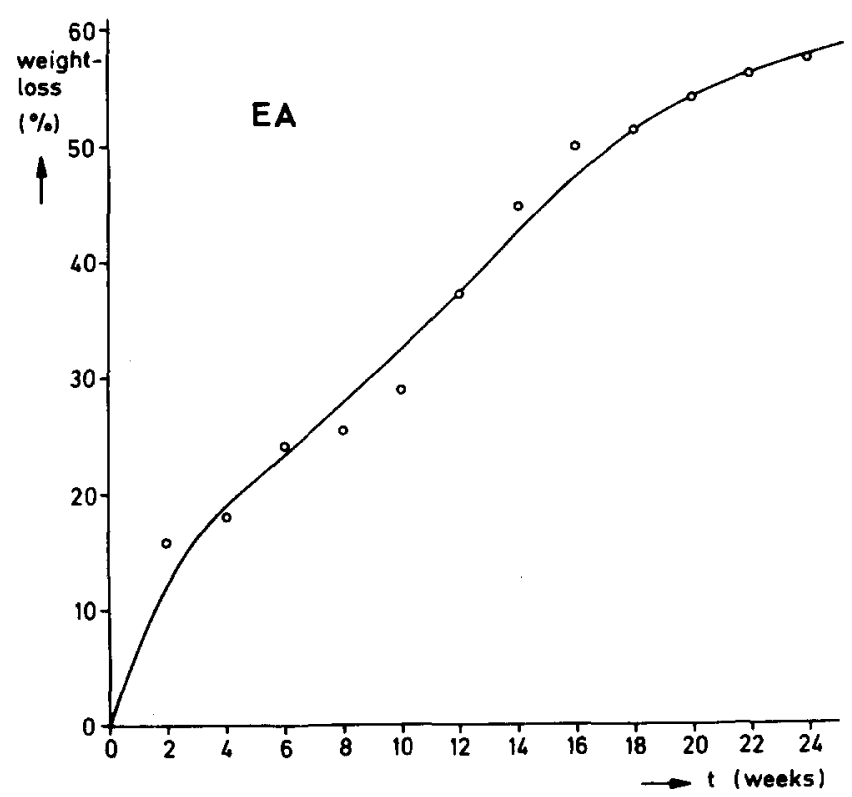

Figure 2: Accumulative weight loss of composted Eucalyptus amygdalina leaves

Abbildung 2: Gewichtsverlustkurve der kompostierten Eucalyptus amygdalina Blätter

Table 2: Elemental analysis of some composted leaves Tabelle 2: Elementaranalyse einiger kompostierter Blätter

\begin{tabular}{llllll}
\hline & C \% & H \% & N \% & C/N & $\mathrm{C} / \mathrm{H}$ \\
\hline EA 0 & 45,78 & 6,205 & 0,965 & 47,44 & 7,04 \\
\hline EA 1 & 43,74 & 6,405 & 1,45 & 33,61 & 7,58 \\
\hline EA 11 & 43,125 & 5,78 & 2,31 & 18,67 & 7,46 \\
\hline SA 0 & 44,44 & 6,42 & 1,18 & 37,7 & 6,92 \\
\hline SA 1 & 43,86 & 6,23 & 1,55 & 28,3 & 7,04 \\
\hline SA 11 & 36,80 & 4,83 & 2,49 & 14,78 & 7,63 \\
\hline
\end{tabular}


Similar trends are observed for all other composted leaves and needles. The spectra from all starting materials are presented as histograms in Figure 3. From these data, it is evident that during the process of composting, only the intensity ratios of the various signals undergoe changes and that there is no occurrence of any new signals that would otherwise be indicative of new type of carbon-containing compounds having formed. By and large, the histograms plotted for the different plant materials show surprising similarity. The most plausible assignments for the carbon- 13 resonances in Figure 3 are given in Table 3. Signals ascribable to aromatic lignine structures appear to be missing, and the $\mathrm{OCH}_{3}$ signals which are otherwise very prominent in typical lignine spectra (Lüdemann et al., 1974) are not observed, either. In view of the results obtained from the chemical analysis of the leaves, which reveals a fairly high lignine content, this finding is rather unexpected. The weak signals at 130 and $119 \mathrm{ppm}$ are most plausibly explained by $\mathrm{sp}^{2}$ carbons in aliphatic or alicyclic structures. The spectra presented in Figure 1 clearly show that during the process of humification, all $\mathrm{C}-13$ signals are broadened significantly. This observation is typical of all products studied hitherto. The spin-spin relaxation obviously becomes more efficient during decomposition of the starting material. Three likely explanations have been offered for this in the literature:

1. An increase in the concentration of paramagnetic free organic radicals.

2. A reduction of the molecular mobility of the dissolved molecules.

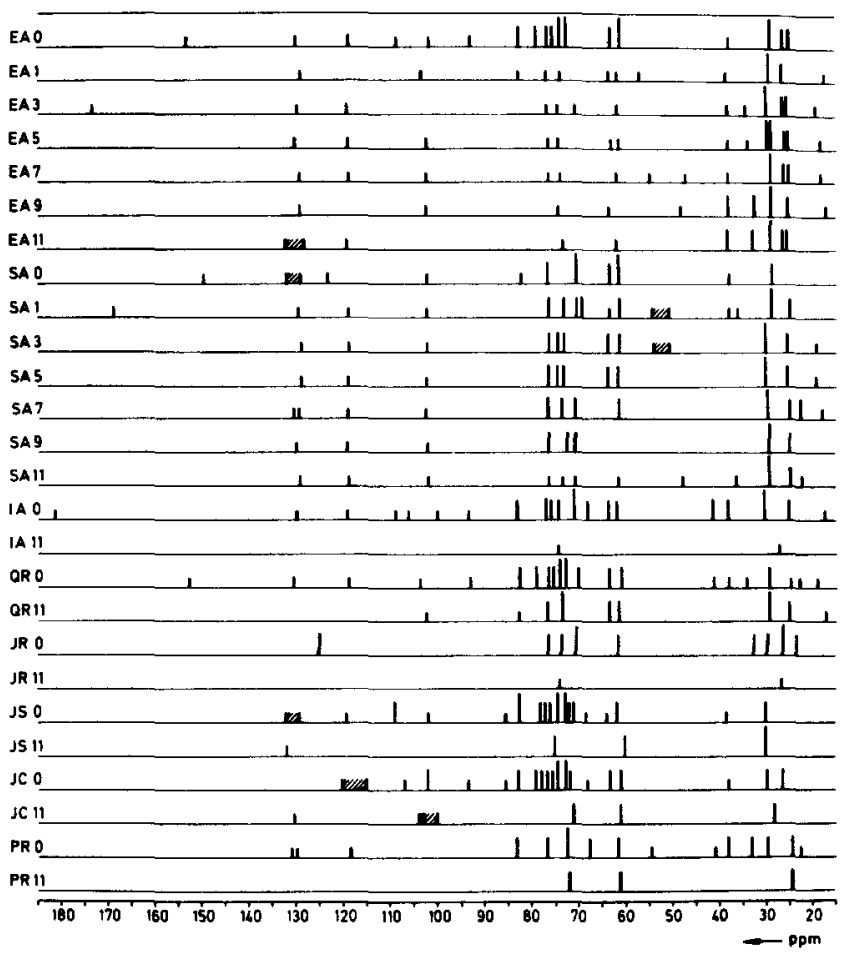

Figure 3: Stick diagrams of the various C-13 spectra obtained from the composted leaves. The abbreviations are given in the text.

Abbildung 3: Histogramme der C-13 Spektren von verschiedenen kompostierten Blättern. Die Abkürzungen sind im Text erklärt.
3. An increase in the chemical heterogeneity of the samples during the composting processes.

The first possibility was examined by carrying out quantitative ESR measurements on three probes from EA leaves. Table 4 gives the results. It is obvious from these data that the spin concentration does not undergo any significant change during the humification process, which thus rules out this first explanation.

It cannot be decided whether either of the possibilities 2 and 3 or, what is perhaps more likely a combination of both, is responsible for the effects observed since reliable data on the molecular weight distribution in the samples and on the extent of cross-linking and reduction in side-chain mobility are still wanting.

Table 3: Most plausible assignments of the various C-13-signals in the composts of Fig. 3

Tabelle 3: Mögliche Zuordnungen der C-13 Signale von Fig. 3

Chemical Possible assignments

shift

(ppm)

$\left.\begin{array}{l}130 \\ 119\end{array}\right\} \begin{aligned} & \mathrm{sp}^{2} \text {-carbon/lignine structures must be excluded since } \\ & \text { the typical } \mathrm{OCH}_{3} \text { signal at } 56 \mathrm{ppm} \text { is missing }\end{aligned}$

\section{CARBOHYDRATE SIGNALS}

$102 \quad \mathrm{C}-1^{\prime}$ in cellobiose $(102,4) \mathrm{C}-1$ in amylose $(102,9)$

$93 \quad \mathrm{C}-1$ in $\alpha-(91.7)$ resp. $\beta$ - (95.6) cellobiose

82.5 C-4 in amylose (80.3), glycosidic $\mathrm{C}-\mathrm{N}$ bond, other bond

$76.8 \quad \mathrm{C}-2$ in amylose

$75.7 \quad \mathrm{C}-2 / \mathrm{C}-5$ in cellobiose $(75.4 / 75.8)$

$74 \quad \mathrm{C}-3 / \mathrm{C}-5$ in amylose $(74.8 / 74.6)$ C- $\beta-3, \mathrm{C}-\beta-5$ cellobiose (74.1/74.6)

$72.8 \quad C-\beta-2$ C-2' in cellobiose (73.8/73.0)

$70.8 \quad \mathrm{C}-\alpha-2 / \mathrm{C}-\alpha-3 / \mathrm{C}-\alpha-5 / \mathrm{C}-4^{\prime}$ in cellobiose $(69.9 / 71.1 / 71.2 / 69.3)$

$67.9 \quad \mathrm{C}-6$ in a 1 ' -6 in melibiose or amylopectin residues

63.4 C-6 in amylose (63.4) C- $\beta-6 / C-\alpha-6$ in glucose (63.7/63.6)

$61.5 \quad C-6^{\prime} / C-\alpha-6 / C-\beta-6$ in cellobiose $(60.5 / 60.0 / 59.8)$

\section{ALKANE CARBONS}

$37.8 \quad \mathrm{C}-3$ in $\mathrm{C}-2$ methylated long chain alkanes

28.8 $\quad \mathrm{CH}_{2}$ groups in long alkane chains

26.1 C-4 in C-2 methylated long chains

$25.0 \quad$ alkanes

In brackets literature values: (Breitmaier and Voelter, 1974) resp. (Bremser et al., 1981).

Table 4: Quantitative ESR measurements on three probes from EA leaves.

Tabelle 4: Quantitative ESR-Messungen an drei EA-Proben.

\begin{tabular}{ll}
\hline Samples & Spin concentration \\
\hline EA 0 & $2.30 \cdot 10^{17}$ spins $/ g$ \\
EA 1 & $1.75 \cdot 10^{17}$ spins $/ g$ \\
EA 11 & $2.32 \cdot 10^{17}$ spins $/ g$ \\
\hline
\end{tabular}




\section{Humic acids from defined composts}

\subsection{Grapevine prunings mixed with grape husks}

As stated in the Materials and Methods section, the composts from grapevine prunings, grape husks and wheat straw were extracted to obtain the humic acid fraction. The carbon-13 spectra for the humic acids from composts prepared from grapevine prunings mixed with grape husks are compiled in the histograms in Figure 4. The spectra are surprisingly similar considering the different starting materials. Degenerative methods gave similar results, i.e. no differences between the different additives used for compo- sting. The ,humic acids“ are similar to an oxidatively altered lignine polymer rather than to true humic acids produced in soil. The most plausible interpretation of the prominent lines is given in Table 5. The main part of the spectra is described by a combination of aliphatic- and lignine-like structures. The comparison of the spectra given in Figure 5 shows that the change of the spectra with time is slow. During the process of composting, the lignine group of signals decreases in intensity while the aliphatic structures become more prominent. This finding is corroborated by previous studies of Haider et al. (1985). There is no indication of any influence having been exerted on the spectra by the various additives used for nitrogen enrichment.

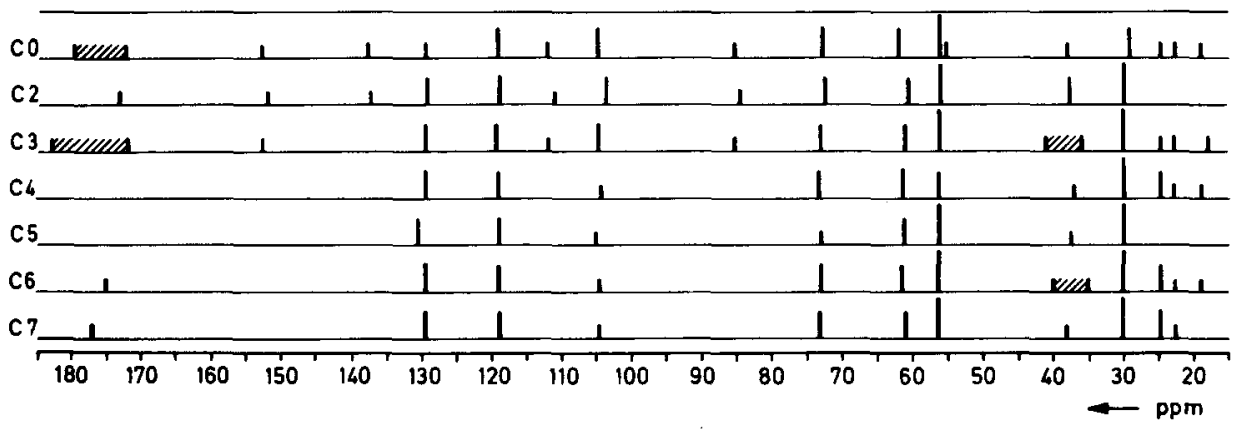

Figure 4: Stick diagrams of the various $\mathrm{C}-13$ spectra obtained from humic acids prepared from composted vine shoots mixed with grape husks.

Abbildung 4: Histogramme der C-13 Spektren von den Huminsäuren aus kompostiertem Weinrebenbeschnitt vermischt mit Trester.
Table 5: Most plausible assignments for the C-13 spectra of the composts in Fig. 4

Tabelle 5: Mögliche Zuordnungen für die C-13 Spektren der in Fig. 4 dargestellten Komposte

Chemical

Possible assignments

shift

(ppm)

$\mathrm{C}=0$ in aliphatic structures or carboxyl groups

C-3/C-5 in syringyl structures with an ether bond at C-4

$\mathrm{C}-1 / \mathrm{C}-4$ in syringyl structures with an ether bond

$129 \mathrm{C}-1$ syringyl or guajacyl units with an $\alpha-\mathrm{CH}=\mathrm{CH}$-or sec. $\alpha-\mathrm{CH}$

$\mathrm{C}-1$ in phenylcumarane, C-2/C-6 in p-hydroxyphenol

119 C-6 in guajacyl structures

$112 \mathrm{C}-2$ in guajacyl structures

$105 \mathrm{C}-2 / \mathrm{C}-6$ in syringyl structures

$85 \quad C-\alpha$ in pinoresinol structures $C-\beta$ in phenylglycerol $-\beta$ arylethers, $C-\beta$ in arylethers with $\alpha C=0$

$73 \mathrm{C}-\alpha$ in $\beta$-arylethers, $C-\gamma$ in dinbenzyltetrahydrofuraneunits and in pinoresinol units

$61 \mathrm{C}-\gamma$ in $\beta$-arylethers $\mathrm{OCH}_{3}$ in $\mathrm{C}-4$ positions of syringyl units. $\mathrm{C}-\mathrm{OH}$ in aliphatic alcohols

$56 \mathrm{OCH}_{3}$ at $\mathrm{C}-3 / \mathrm{C}-5$ of syringyl resp. $\mathrm{C}-3 / \mathrm{C}-4$ of guajacyl units or $\mathrm{C} \cdot 2$ in amino acids

$35-41$ aliphatic carbons vicinal to $-\mathrm{C}-\mathrm{OH}$ or $-\mathrm{C}-\mathrm{NH}_{2}$

$\left.\begin{array}{l}\left.\begin{array}{l}30 \\ 25\end{array}\right\} \text { aliphatic structures }\left(\mathrm{CH}_{2} \text {-groups in long chains) }\right. \\ 23 \\ 19\end{array}\right\}$ methylgroups

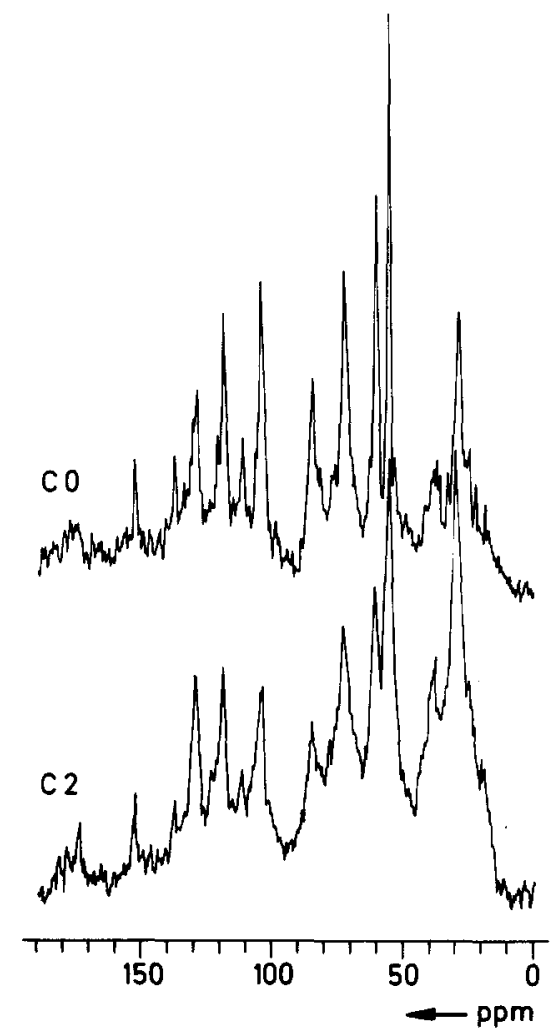

Figure 5: Change of C-13 spectra of humic acids prepared from composted vine shoots and grape husks with time. Above starting material, below after 4 months incubation.

Abbildung 5: Veränderung der C-13 Spektren der Huminsäuren aus Weinrebenbeschnitt und Trester. Oben Ausgangsmaterial, unten nach 4 Monaten Inkubationszeit. 
The comparison of the aliphatic part of the two groups of substances (the composted needles and leaves and the humic acids described above) shows significant differences in the distribution of the relative intensities and chemical shifts. Both classes of compounds have a surprisingly small intensity in the chemical shift range of methyl groups. In our opinion this indicates that alicyclic structures or longer alkane chains contribute most to the aliphatic part of the spectra.

\subsection{Composts from grape husks}

Typical spectra for these products are compiled in Figure 6. This histograms of all products studied are given in Figure 7. Comparison of the spectra in Figures 5 and 6 shows

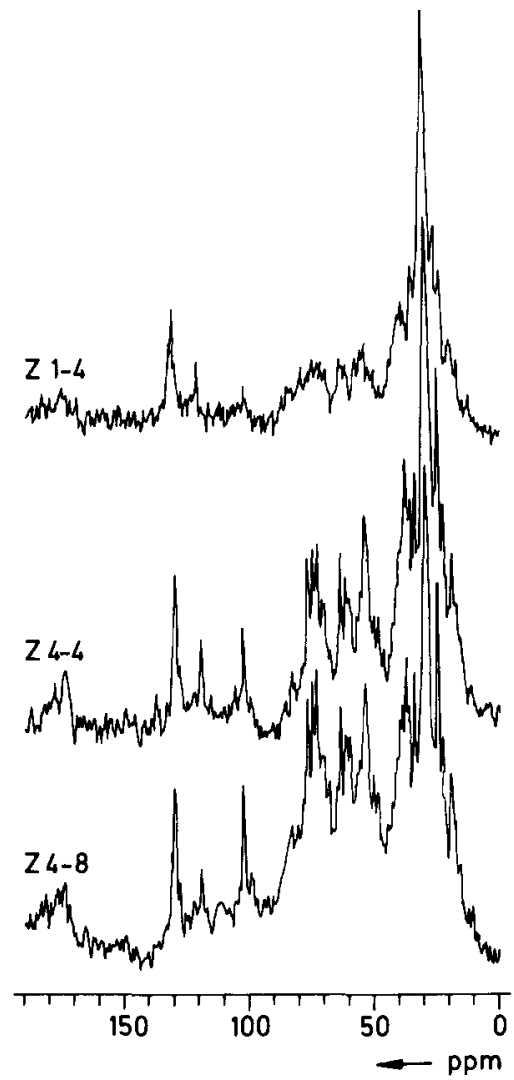

Figure 6: C-13 spectra of humic acids from composted grape husks and seeds. For abbreviations see Table 1.

Abbildung 6: C-13 Spektren von Huminsäuren aus Trester- und Samenkomposten. Abkürzungen siehe Tabelle 1. significant differences between the two groups of spectra. The aliphatic and carbohydrate regions of grape husks composts are more intensive than in the former group of composts. Lignine structures are almost completely missing, as evidenced by the absence of the methoxyl peak at $56 \mathrm{ppm}$. These presence of chicken dung slows down the decomposition processes, since the spectrum $\mathrm{z}$ 4-8 obtained after 2 months of composting shows still more structure than the humic acids derived from the neat starting materials after two months. The chicken dung obviously acts as a mild bactericide or fungicide. Qualitatively, however, the spectra are very similar and the addition of chicken dung obviously does not lead to different products in the humification process.

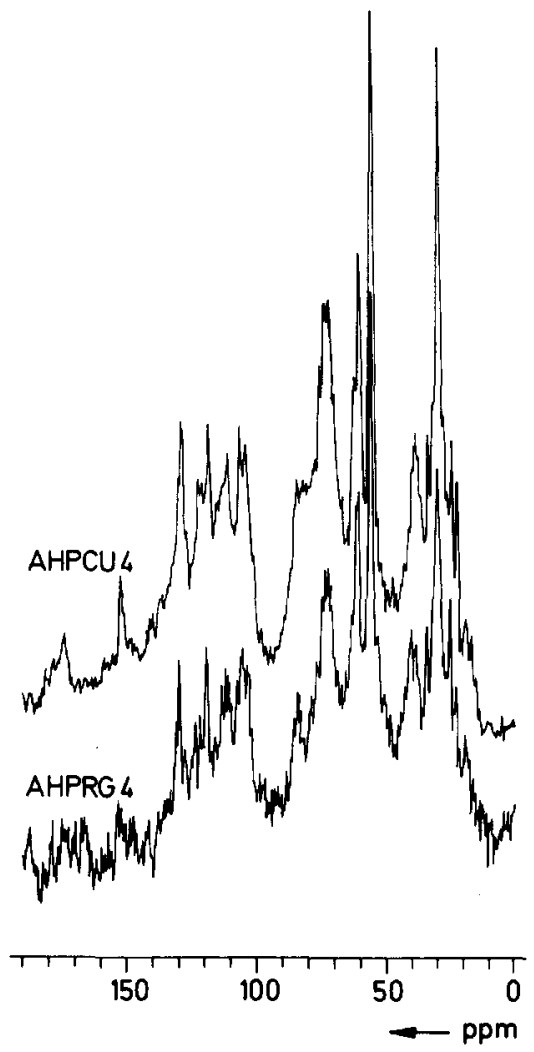

Figure 8: C-13 spectra of humic acids prepared form composted wheat straw with different additives. For abbreviations see Table 1

Abbildung 8: C-13 Spektren von Huminsäuren aus kompostiertem nassen Stroh mit verschiedenen Zusätzen. Abkürzungen siehe Tabelle 1 .

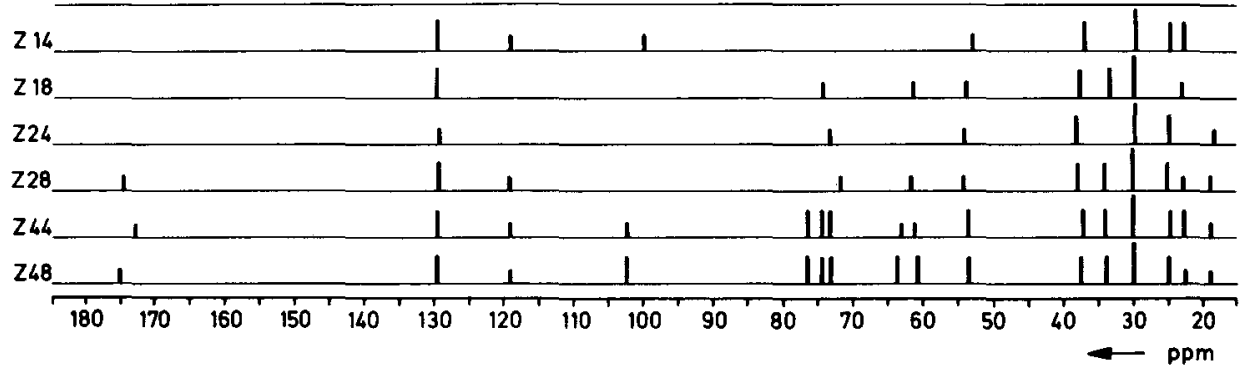

Figure 7: Stick diagrams of the various $\mathrm{C}-13$ spectra obtained from humic acids prepared from composted grape husks and seeds.

Abbildung 7: Histogramm der C-13 Spektren von Huminsäuren aus kompostiertem Trester und Samen. 
Table 6: Plausible assignments of the C-13 spectra of humic acids derived from wheat straw.

Tabelle 6: Mögliche Zuordnungen für die C-13 Spektren der aus Weizenstroh erzeugten Huminsäuren

\begin{tabular}{ll}
\hline $\begin{array}{l}\text { Chemical } \\
\text { shift } \\
(\mathrm{ppm})\end{array}$ & \multicolumn{1}{c}{ Possible assignments } \\
\hline 129.4 & $\begin{array}{l}\text { aromatic-carbons } \mathrm{C}-1 \text { in phenylcumarane } \\
\mathrm{C}-2 / \mathrm{C}-6 \text { in p-hydroxyphenyl, or } \\
\mathrm{sp}^{2} \text {-carbons } \mathrm{C}-\beta \text { in cinnamic alcohol. }\end{array}$ \\
119 & $\mathrm{C}-6$ in guajacyl \\
61.4 & $\mathrm{C}-\gamma$ in $\beta$-arylethers $\mathrm{OCH}_{3}$ in syringyl $\mathrm{C}-4$ \\
56.5 & $\mathrm{OCH}$ \\
$40-38$ & $\mathrm{CH}-$ in iso-propylketones \\
34 & $\mathrm{C}-\alpha$ in aryl- $\mathrm{CH}_{2}-\mathrm{CH}_{2}-\mathrm{CH}_{2} \mathrm{OH}$ \\
30 & $-\mathrm{CH}_{2}-$ in long chain alkanes \\
25 & $\mathrm{CH}_{3}$ in acctophenone structures \\
\hline
\end{tabular}

\subsection{Humic acids derived from wheat straw}

Figure 8 shows two typical C-13 spectra for this class of compounds. They exhibit great similarity to the spectra presented in Figure 5 for the humic acids from grapevine prunings. The signal typical of lignine structures are very prominent, the main difference being that the spectral region between 100 and $60 \mathrm{ppm}$ is considerably more intense thus indicating that these composts contain a larger amount of residues derived from carbohydrates.

The assignments of the various signals are shown in Table 6 . The addition of nitrogen-containing compounds is again seen to have no influence on the products of the humification process although it does appear to influence the rate of decomposition.

Haider, K., H.W. Kern, E. Ludger (1985): Intermediate Steps of Microbiol. Lignine Degradation as Elucidated by C-13 NMR Spectroscopy of Specifically C-13-Enriched DHP-Lignins; Holzforschung 39, 23-32

Lüdemann, H.-D., H. Nimz (1974): ${ }^{13} \mathrm{C}-$ Kernresonanzspektren von Ligninen, 2; Makromolekulare Chemie 175, 2409-2422

Preston, C.M., B.A. Blackwell (1985): Carbon-13 Nuclear Magnetic Resonance for a Humic and a Fulvic Acid: Signal-to-Noise Optimization, Quantitation, and Spin-Echo Techniques; Soil Science 139, 88-96. 